\title{
Practical Factors Controlling in vitro Adventitious Root Formation from Walnut Shoot Microcuttings
}

\author{
Ramon Dolcet-Sanjuan ${ }^{1}$ and Elisabet Claveria \\ Departament Genètica Vegetal, IRTA Centre de Cabrils, ES-08348 Cabrils (Barcelona), Spain \\ Robert Gruselle \\ Station des Cultures Fruitières et Maraichères, SRFM, BE-5030 Gembloux, Belgium \\ Adreas Meier-Dinkel \\ Neidersächsische Forstliche Versuchsanstalt, Abteilung Forstpflanzenzüchtung, D-34355 Staufenberg- \\ Escherode, Germany \\ Christian Jay-Allemand \\ Station d'Amélioration des Arbres Forestiers, INRA Orléans, FR-45160 Ardon, France \\ Thomas Gaspar \\ Laboratoire d'Hormonologie Végétale, Institut de Botanique B22, Université de Liège-Sart Tilman, \\ BE-4000 Liège, Belgium
}

\begin{abstract}
ADDITIONAL INDEX WORDS. walnut, Juglans regia, J. nigra X J. regia, micropropagation, rejuvenation, auxins, sucrose and carbon dioxide

Aвstract. Various factors were found to influence the in vitro induction and elongation of adventitious roots from walnut shoot microcuttings. Diverse walnut genotypes (Juglans regia, J. nigra $\times$ J. regia hybrids) and selected elite J. regia clones were micropropagated throughout the establishment of in vitro shoot-tip cultures. New evidence is presented here that demonstrates the importance of the genotype and juvenility of the plant material on the in vitro rooting ability. Selection of the best adapted genotypes to multiplication and rooting, and rejuvenation of mature clones through repetitive subcultures or micrografting were examined. Adult $J$. regia clones were rejuvenated through subsequent subcultures and their rooting was consequently improved. The same results were not accomplished by micrografting on juvenile shoots. A differential response to auxin type and concentration was observed for Juglans regia or J. nigra $x$ J. regia clones. A short prerooting culture in multiplication medium, lowering the sucrose concentration in the root elongation medium and increasing the atmospheric carbon dioxide during the root elongation phase affected the number of shoots forming roots as well as the quality of plantlets and roots.
\end{abstract}

Although great progress has been reported on rooting semihardwood and hardwood cuttings of the walnut hybrid Paradox, clonal propagation by cuttings remains limited to some genotypes (McKenna and Sutter, 1997). Walnut trees (Juglans nigra x Juglans regia) were first micropropagated through in vitro culture of zygotic embryos and multiplication by shoot-tip cultures (Cornu and Jay-Allemand, 1989; Jay-Allemand et al., 1992). Explants from vigorously growing seedlings were used in the micropropagation of the walnut rootstock Paradox (J. hindsii X J. regia) (Driver and Kuniyuki, 1984). However, little progress has been made in the micropropagation of adult walnut trees after the methodology published by McGranahan et al. (1988). A modification of that methodology has been used here to establish shoot-tip cultures and further micropropagation of adult J. regia clones.

The micropropagation of walnut trees presents some complications that have to be overcome before this technology is used as a commercial tool for clonal propagation (McGranahan et al., 1987; Rodriguez et al., 1989; Gruselle and Boxus, 1990). Establishment of shoot-tip cultures from selected adult walnut trees, irregular and low multiplication or rooting rates, and high number of losses during acclimatization of plantlets to soil are

Received for publication 12 June 2003. Accepted for publication 5 Nov. 2003 This work was supported in part by the AIR Program of the European Commission (CT92-0142). Use of trade names does not imply endorsement of the products named nor criticism of similar ones not named.

'To whom correspondence should be addressed; e-mail ramon.dolcet@irta.es. the main difficulties. The present work aims to focus on some factors affecting the in vitro formation of adventitious roots on microcuttings. The goal was not only to improve the number of shoots forming roots but also the quality of roots and consequently the acclimatization of plantlets to soil.

\section{Materials and Methods}

Plant material. Twenty-seven J. regia ('SBE1' to 'SBE27') and nine J. nigra X J. regia ('A18', 'A19', 'A32', 'A35', 'A63', 'A65', 'A67', 'A69', and 'M38') juvenile clones were established from embryonic axes in either Dolcet-Sanjuan's laboratory in Cabrils (Spain) or Jay-Allemand's laboratory in Ardon (France), as described in Jay-Allemand and Cornu (1986). Juglans regia zygotic embryos originated from open pollinated crosses with 'MB-T-231' as the maternal component. Morphological characters were used to determine the hybrid origin of the J. nigra $\times J$. regia clones (Jay-Allemand et al., 1990). A German J. regia clone ('192') was established from 2-year-old seedlings.

Mature J. regia clones 'Serr', 'MB-T-31', 'MB-T-40', 'MB-T218', 'MB-T-230', 'MB-T-231', and 'MB-GI-1' were selected for their characteristics as cultivars, rootstocks, or timber production (Aleta and Ninot, 1993). Scions were collected from mature trees and grafted on seedlings of the same species. Grafted trees, 2 to 3 years old, maintained in a greenhouse to reduce the risk of in vitro contamination, were used as source of explants. Other J. regia 
clones ('RG1') were kindly provided by J.C. Navatel (Heloir et al., 1996; Ripetti et al., 1994).

Multiplication MEdium AND CUlture CONDitions. After a preliminar comparison with DKW-C medium (McGranahan et al., 1987), MS medium (Murashige and Skoog, 1962), and woody plant medium (WPM) (Lloyd and McCown, 1980), the DKW medium (Driver and Kuniyuki, 1984) was chosen for the establishment and multiplication (subcultures every 3 weeks) phases. This medium contained the original mineral nutrients, with $0.29 \%$ (w/v) Phytagel, at a pH of 5.5. Growth regulators (BA and IBA) were added to the multiplication medium before autoclaving. Auxins used in the root induction (IBA, IAA, and NAA) medium were dissolved in dimethylsulfoxide (Dolcet-Sanjuan and Claveria, 1995) and added to the medium after autoclaving. During establishment, shoot multiplication, and root elongation all cultures were kept at $28{ }^{\circ} \mathrm{C}$ under a photoperiod of $16 \mathrm{~h}$ of cool-white fluorescent light $\left(70 \mu \mathrm{mol} \cdot \mathrm{m}^{-2} \cdot \mathrm{s}^{-1}\right)$.

EXPLANT ESTABLISHMENT AND SHOOT MULTIPLICATION. Juvenile clones ( $J$. regia or $J$. nigra $\mathrm{x} J$. regia) were established from embryonic axes isolated and introduced in vitro as described by Jay-Allemand and Cornu (1986). Dormant buds were used as explants to establish the J. regia clone '192'. After elimination of bacterial contaminated cultures and taking into account the in vitro multiplication and rooting rates, following the methodology described by Jay-Allemand et al. (1992), nine clones ('SBE11', 'SBE26', 'SBE27', '192', 'M38', 'A18', 'A32', 'A35', and 'A69') were selected and used in rooting trials.

Establishment of in vitro shoot-tip cultures from mature walnut trees was basically accomplished following the methodology described for Pistacia vera L. (Dolcet-Sanjuan and Claveria, 1995).

ROOTING EXPERIMENTS. Rooting assays were performed using a sequence of two rooting media, a root induction one with auxin, followed by another one without auxin but with vermiculite, as proposed by Jay-Allemand et al. (1992) and already used beneficially by Ripetti et al. (1994), Heloir et al. (1996) and Gatineau et al. (1997). The latter culture system was chosen for subsequent rooting assays. Briefly, the DKW (Driver and Kuniyuki, 1984) medium with one-fourth the concentration of macronutrients and with no glutamine was used as rooting medium. Root induction was performed by culture for $5 \mathrm{~d}$ in rooting medium supplemented with an auxin. The efficacy of three auxins (IBA, NAA, or IAA) to induce rooting in different walnut clones ('Serr', 'A18', and 'A69') was studied at five concentrations $(1,3.2,10,32$, or $100 \mu \mathrm{M})$. The auxins were dissolved in dimethylsulfoxide (Dolcet-Sanjuan and Claveria, 1995) and added to the medium after autoclaving. Each flask contained $100 \mathrm{ml}$ of medium and five shoots (3 to 5 $\mathrm{cm}$ long) proceeding from multiplication cultures. At this stage cultures were kept in the dark. Root elongation was achieved after culture for 3 weeks in auxin-free medium and light conditions as in the multiplication phase. The root elongation medium consisted in a mixture of vermiculite and Gelrite $(0.25 \%, \mathrm{w} / \mathrm{v})$ moistened with DKW base diluted four times. The percentage of shoots forming roots, number and length of primary roots per rooted shoot, and number of secondary roots were scored.

The in vitro rooting ability of 14 juvenile clones ('A18', 'A32', 'A35', 'A69', 'M38', 'SBE4', 'SBE5', 'SBE11', 'SBE15', 'SBE21', 'SBE22', 'SBE26', 'SBE27', '192') and two mature clones ('Serr' and 'MB-T-231') was examined in a first experiment. After root elongation, the percentage of shoots forming roots was scored.

The beneficial effects of rejuvenation on rooting were de- termined by in vitro micrografting the mature J. regia 'Serr' on seedlings of the same species. Micrografts were performed with the help of a silicon tube to hold together scion and rootstock. When the scion elongated enough, this was excised, subcultured, and a second grafting was performed. Root induction in microcuttings derived from none, one, or two micrografts, was done in the presence of $25 \mu \mathrm{M}$ IBA. After root elongation, the percentage of shoots forming roots was scored.

The effects of subsequent multiplication subcultures on rooting of mature (J. regia 'Serr' and 'MB-T-231') or juvenile ('A18', 'A69', 'SBE26', and '192') clones were also studied. The number of subcultures in multiplication medium depended on the clone and ranged from 6 to 63 . Root induction was done in the presence of $25 \mu \mathrm{M}$ IBA, except for J. regia '192', which was induced in $15 \mu \mathrm{M}$ IBA.The percentage of shoots forming roots was scored after root elongation.

An experiment was performed to test the effects of three atmospheric carbon dioxide concentrations (1000, 2000, and $\left.4000 \mu \mathrm{L} \cdot \mathrm{L}^{-1}\right)$, and three sucrose levels in the culture medium (30, 15 and $\left.0 \mathrm{~g} \cdot \mathrm{L}^{-1}\right)$, on the root elongation of three walnut clones ('Serr', 'A18', and 'A69'). Rooting was induced with a $32 \mu \mathrm{M}$ IBA treatment for 'A18' and 'A69' and a $32 \mu \mathrm{M}$ NAA for 'Serr' microcuttings. Shoots were grown on auxin-containing medium for $5 \mathrm{~d}$ and then on auxin-free medium for 3 weeks. During root elongation cultures were incubated in plexiglass boxes with periodic inflow of air containing $\mathrm{CO}_{2}$. Air was renewed every 24 h. Control samples were held in ambient air (not renewed) that contained $\mathrm{CO}_{2}$ at $340 \mu \mathrm{L} \cdot \mathrm{L}^{-1}$ After root elongation, the percentage of shoots forming roots, number of primary roots per rooted shoot, and number of secondary roots were scored.

The effects of temperature $\left(22\right.$ or $\left.27^{\circ} \mathrm{C}\right)$, during both the root induction and elongation phases, were determined for two hybrid clones ('A32' and 'A35'). The percentage of shoots forming roots was scored after culture in the G60 medium (Gruselle and Boxus, 1990; Gruselle et al., 1995), gellified with Pastagar B (Diagnostics Pasteur, Paris).

Finally, the influence of a 2-week-long culture in fresh G60 multiplication medium right before the root induction phase was studied with two J. nigra X J. regia clones ('A32' and 'A35'). The standard G60 multiplication medium was supplemented with 4.4 $\mu \mathrm{M}$ BA. A lower concentration of BA $(0.44 \mu \mathrm{M})$ was also tested during this prerooting conditioning culture. The percentage of shoots forming roots was scored.

Each experiment, with a completely randomized design, consisted of three to five randomly selected replicate flasks with five shoots each per treatment level. Depending on the experiment, three to five repetitions were performed. Statistical tests included analysis of variance, separation of means by Fisher's protected LSD, and planned contrasts (Petersen, 1985). Auxin concentrations were equally spaced on a logarithmic scale. Regression trends were obtained using orthogonal polynomial contrasts. The polynomial coefficients to partition the treatment sum of squares (SST) into components associated with successive terms of a polynomial equation and the regression equation were calculated according to Carmer and Seif (1963).

Acclimatization to soil. Rooted plantlets were washed and potted in trays with $200-\mathrm{mL}$ conical wells, containing steamsterilized $\left(100{ }^{\circ} \mathrm{C}, 1 \mathrm{~h}\right)$ substrate ( 2 peat : 1 perlite, by volume). Plantlets were acclimatized for 3 weeks in plastic boxes, gradually opened during the last week to lower the humidity. Four weeks later, the number of acclimatized plants was scored. At this stage, plants with new leaves along with an extensive root system were 
repotted into 16-cm-wide polypropylene containers with another substrate ( 2 peat : 1 sand, by volume). Plants were maintained in a shaded greenhouse till they were transferred to a nursery at the end of the following winter.

\section{Results and Discussion}

EXPLANT ESTABLISHMENT AND SHOOT MULTIPLICATION. Establishment and multiplication of mature J. regia clones ('Serr', 'MB-T-218', 'MB-T-230' and 'MB-T-231') were successfully accomplished with the methodology described here. Juvenile $J$. regia ('SBE11', 'SBE26', 'SBE27') or J. nigra $\mathrm{X}$ J. regia ('M38', 'A69' and 'A18') clones presented scarce problems of contamination during establishment, and satisfactory multiplication rates (1.5 to 2.5). Shoot-tip cultures, maintained in the DKW medium (Driver and Kuniyuki, 1984), were a good source of microcuttings for rooting and acclimatization experiments.

AdDition OF VERMiculite TO THE ROOT ELONGATION MEDIUM. Important to recall is that the use of a single gelified rooting medium allowed only a few malformed and unfunctional roots to be formed on the shoots. The use of a vermiculite containing medium (Jay-Allemand et al., 1992) as a second medium for the root elongation phase improved rooting, number of roots, root elongation, and formation of secondary roots of J. nigra $\mathrm{x} J$. regia hybrids, and J. regia clones. In these conditions, the formation of callus in the shoot base was reduced and a good vascular connection with the root system was proved (Heloir et al., 1994) (Figure 1 ). The sequence of the two rooting media thus was used for the comparison of the rooting abilities.

GENOTYPIC DIFFERENCES ON ROOTING ABILITY. Rooting ability differences among walnut clones were observed (Fig. 2). Significant differences in root formation were observed among embryo derived J. regia clones. Three of them, 'SBE11', 'SBE26', and 'SBE27', reached values of $25 \%$ to $40 \%$ of shoots forming roots. Significant differences on rooting ability were also observed among juvenile $J$. nigra $\times$ J. regia clones. Higher rooting percentages (40\% to $70 \%$ ) were obtained with these clones than with embryo derived J. regia clones. An explanation for these differences could

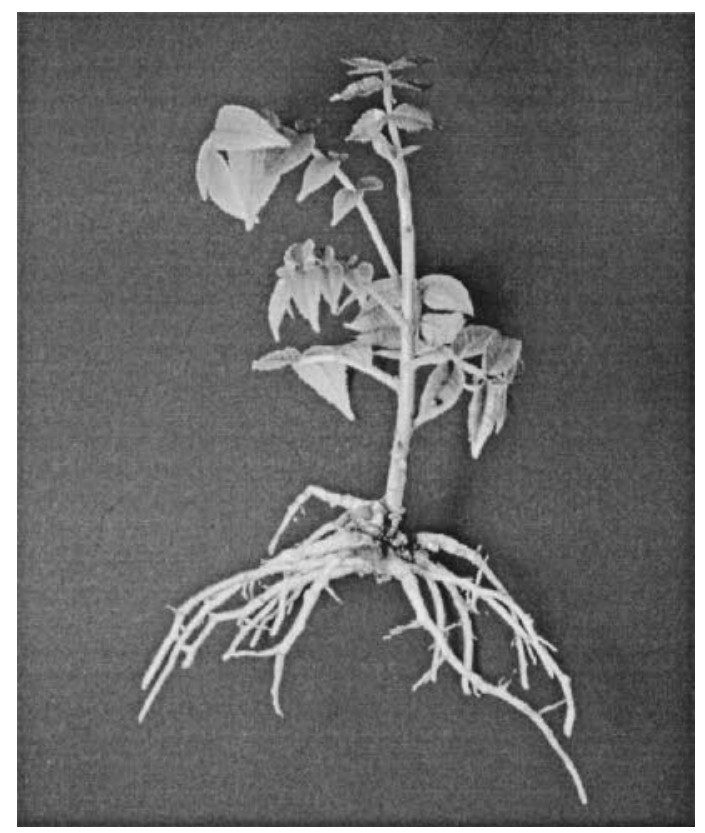

Fig. 1. Rooted walnut shoot after 3 weeks in vermiculite containing medium. be found in the use of a root induction medium designed for $J$. nigra $\mathrm{x}$ J. regia clones (Jay-Allemand et al., 1992) but not optimized for J. regia clones. The percentage of shoots forming roots was lower for mature J. regia 'Serr' and 'MB-T-231' (40 and 5\%, respectively) than juvenile J. regia ('SBE11', 'SBE26', 'SBE27' and '192') or J. nigra X J. regia clones ('A18', 'M38', and 'A69'). A great variation between successive subcultures was observed in the rooting of J. nigra $\times$ J. regia or J. regia clones. Selection of the best adapted clones to the in vitro culture conditions was a questionable but useful solution to improve the rooting rates.

EFFect of JUVENILITY ON RoOTING. Comparing the rooting ability of embryo or seedling derived material with mature clones, juvenility was found to have a dramatic effect on rooting. Embryo derived clones had good response to root induction even at early stages of multiplication. However, it took more than thirty

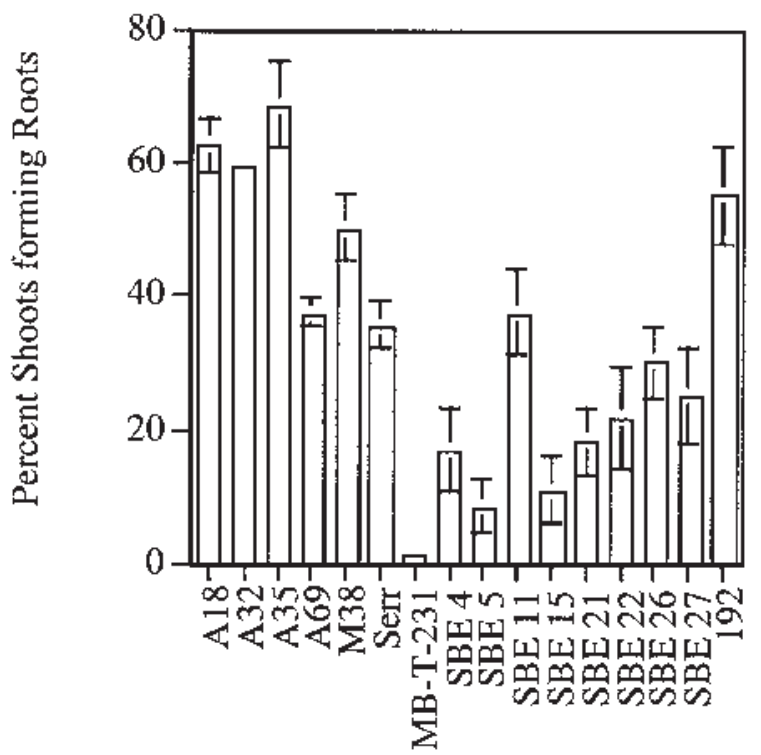

Fig. 2. Percentage of shoots forming roots for different Juglans regia and J. nigra $x$ J. regia clones. Average of 3 repetitions with 25 shoots each per clone.

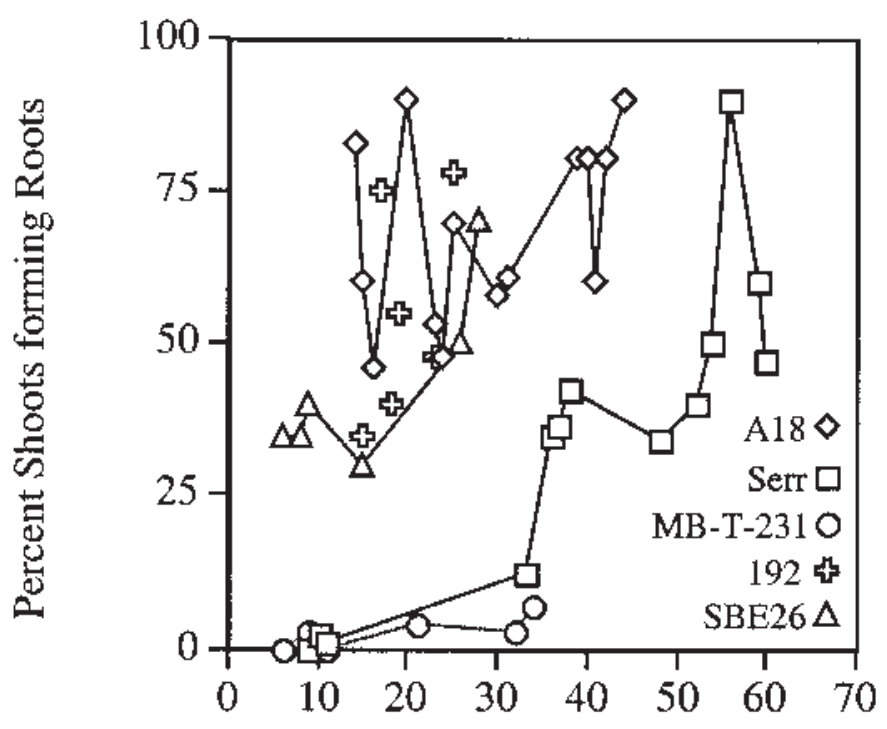

\section{Subculture in Multiplication Medium}

Fig. 3. Effect of number of subcultures in multiplication medium on the percentage of shoots forming roots for different walnut clones. 
subcultures before J. regia mature clones ('Serr', 'MB-T-231') reached a $40 \%$ rooting, similar to that obtained with embryo ('A18', 'SBE26') or seedling ('192') derived J. regia clones only after five subcultures in multiplication medium. Associated with a progressive rejuvenation of the plant material, rooting of the mature clone 'Serr' increased with the number of subcultures in multiplication medium (Fig. 3). Juglans regia 'Serr' showed a significant increase after the 30th subculture in multiplication medium. Aiming to accelerate rejuvenation, J.regia 'Serr' derived from adult material was micrografted on shoots of the embryo derived cultures. The micrografting technique was successful.

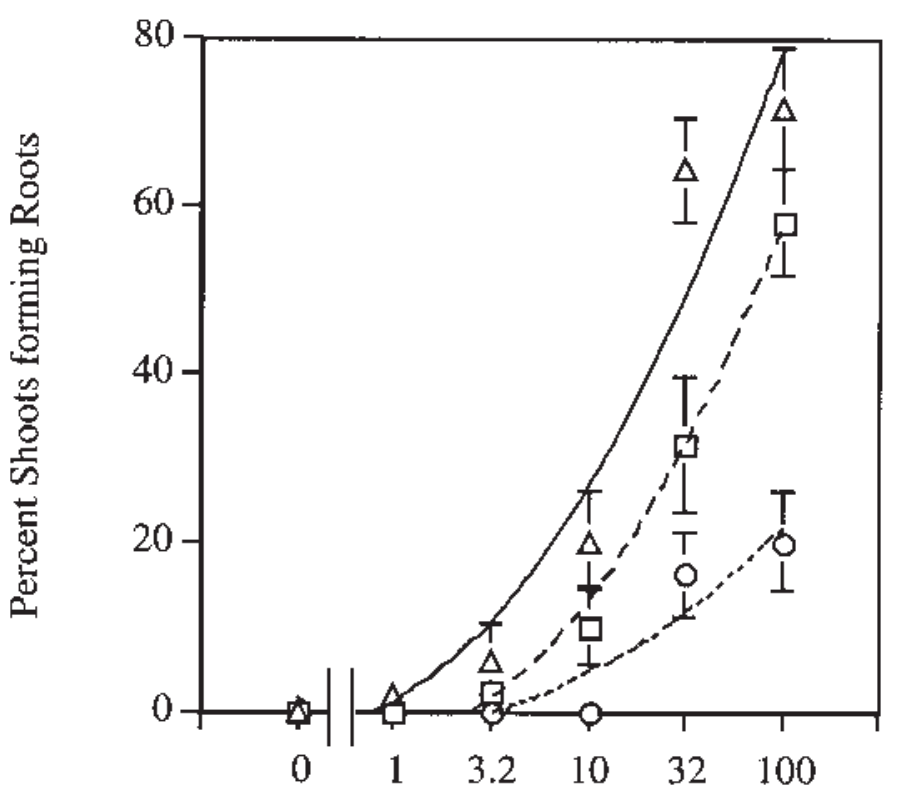

Auxin $(\mu \mathrm{M})$

Fig. 4. Effects of the concentration (log scale) of IBA $(\Delta)$, NAA ( $\square$ ), and IAA $(O)$ on the percentage of Juglans nigra $\times$ J. regia 'A69' shoots forming roots. Vertical bars $=$ SE. The polynomial regression trend was quadratic for IBA $(P$ $<0.001)$, NAA $(P<0.001)$ and IAA $(P=0.048)$.

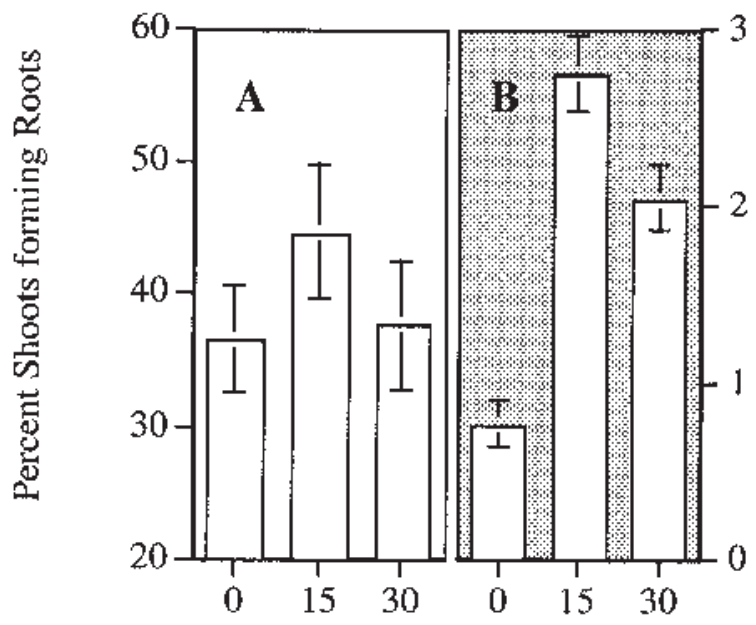

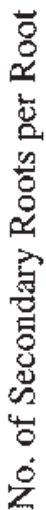

\section{Sucrose $(\mathrm{g} / \mathrm{l})$}

Fig. 5. Effect of sucrose concentration in the root elongation medium on (A) the percentage of shoots forming roots, and $(\mathbf{B})$ the number of secondary roots per root of Juglans regia 'Serr'. Vertical bars $=$ SE.
However, no significant increase in the percentage of shoots forming roots was obtained after one or two successive micrografts.

AUXIN TYPE AND CONCENTRATION FOR ROOT INDUCTION. Rooting of walnut shoots was completely dependent on the application of exogenous auxin (Fig. 4) (Heloir et al., 1996). Rooting was improved by optimizing for each clone the auxin type and concentration during the root induction phase. Selection of the auxin type and optimization of its concentration resulted in some differences with respect to the $25 \mu \mathrm{M}$ IBA proposed by Jay-Allemand et al. (1992). Microcuttings of the J. nigra $\times$ J. regia 'A69' had the highest percentage of rooted shoots (Fig. 4) and number of primary roots per rooted shoot, when IBA

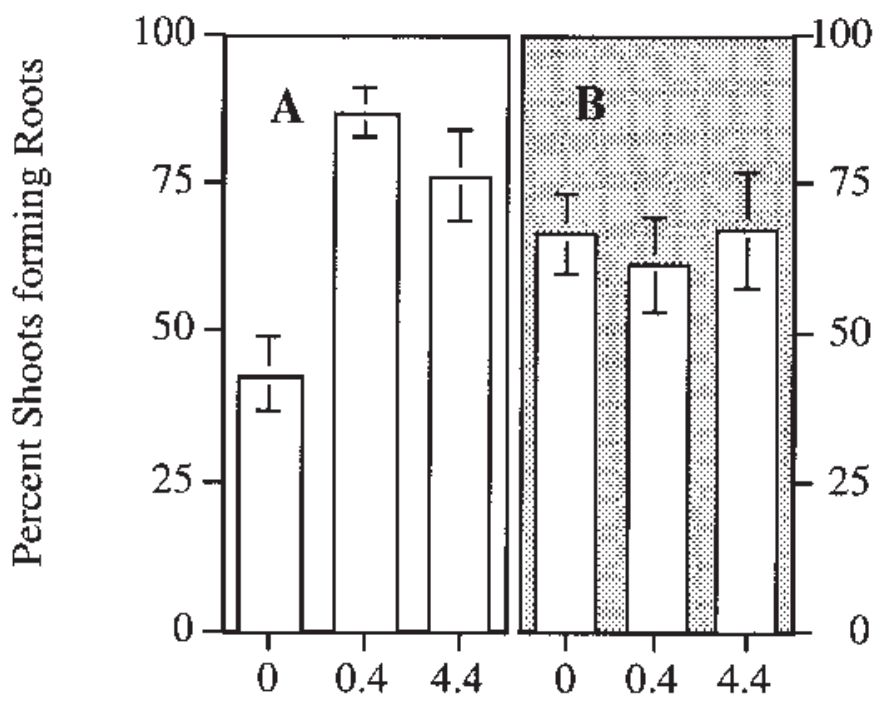

\section{$\mathrm{BA}(\mu \mathrm{M})$}

Fig. 6. Effects of a prerooting culture in multiplication medium with 0.4 or 4.4 $\mu \mathrm{M}$ BA on the percentage of shoots of (A) Juglans nigra $\times$ J. regia 'A32', and (B) 'A35', forming roots. Vertical bars = SE.

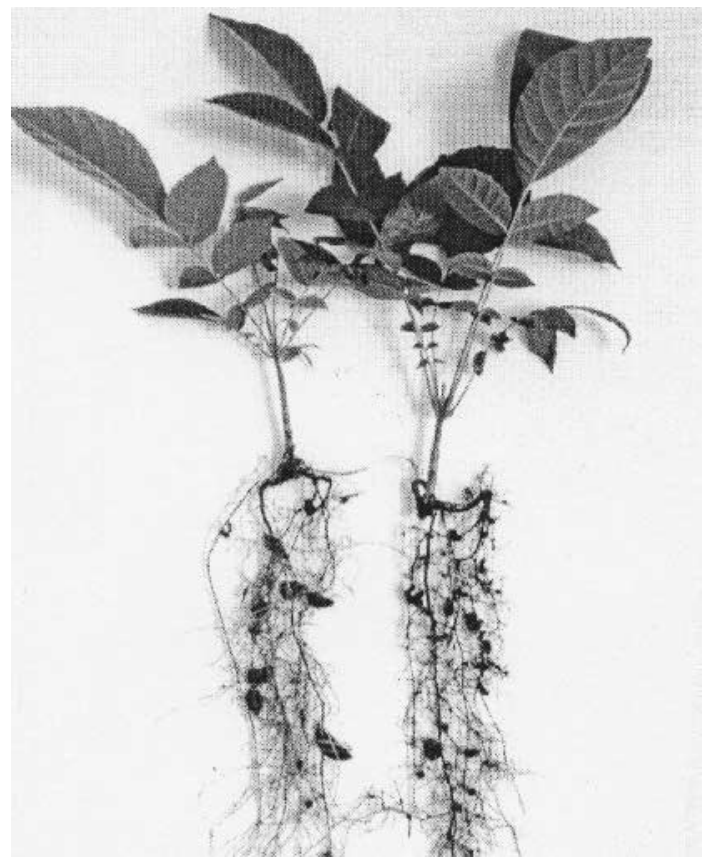

Fig. 7. Micropropagated walnut plant of Juglans nigra $\times$ J. regia 'A18', 1 month after acclimatization. 
was used at 32 or $100 \mu \mathrm{M}$. At these concentrations, the use of NAA or IAA induced a lower percentage of rooted shoots, and number of primary roots per rooted shoot, than with IBA in the root induction medium. Moreover, the number of secondary roots per rooted shoot, a character related with a higher survival in the acclimatization phase (Dolcet-Sanjuan et al., 1996), was higher with the use of IAA than IBA or NAA. However a different response was observed with J. regia 'Serr' microcuttings. With this clone, the percentage of microcuttings forming roots and number of adventitious primary roots per rooted shoot were the same when IBA or NAA were added to the root induction medium, and always higher than with IAA as auxin. The optimal concentrations, with no differences between them, were 32 and $100 \mu \mathrm{M}$. A significantly better response of 'Serr' microcuttings to NAA than IBA was supported by longer adventitious primary roots and higher number of secondary roots per rooted shoot (data not shown). Consequently, IBA and NAA were adopted as the best auxins for root induction in J. nigra $\times$ J. regia and J. regia respectively. A $32 \mu \mathrm{M}$ concentration was preferred over the 100 $\mu \mathrm{M}$, because the latter concentration induced more callus at the shoot base, and root elongation and the formation of secondary roots were strongly inhibited.

SUCROSE LEVEL AND CARBON DIOXIDE ENRICHMENT DURING ROOT ELONGATION. The percentage of microcuttings forming roots (Fig. $5 \mathrm{~A})$ as well as the number of primary roots per rooted shoot were increased when the sucrose level in the root elongation medium was reduced to one half $\left(15 \mathrm{~g} \cdot \mathrm{L}^{-1}\right)$. These effects were independent of the genotype used ( . nigra $\times$ J. regia 'A18' and 'A69', or J. regia 'Serr'). The beneficial effects of a lower sucrose level were also found in the number of secondary roots per rooted shoots (Fig. 5B), a characteristic that was associated with a better acclimatization of plantlets to soil conditions (see Gruselle et al., 1995).

The effect on rooting of the atmospheric carbon dioxide enrichment was dependent on the genotype and interacted with the level of sucrose (data not shown, see Gruselle et al. 1995). Microcuttings of J. nigra X J. regia 'A69', in a root elongation medium with 30 $\mathrm{g} \cdot \mathrm{L}^{-1}$ sucrose, formed roots in a higher frequency when the carbon dioxide level was not increased. However, when no sucrose was present in the medium, carbon dioxide enrichment was beneficial at all levels, and optimal at 1000 or $2000 \mu \mathrm{L} \cdot \mathrm{L}^{-1}$. These effects were not that apparent with J. regia 'Serr' or J. nigra $\times$ J. regia 'A18', for which carbon dioxide had no effect on rooting and no interaction with the level of sucrose in the medium. The number of secondary roots per rooted shoot of J. regia 'Serr' was highest when carbon dioxide was 1000 or $2000 \mu \mathrm{L}^{-1} \mathrm{~L}^{-1}$ and the level of sucrose was $15 \mathrm{~g} \cdot \mathrm{L}^{-1}$. This was also true for J. nigra $\times$ J. regia 'A69' when the level of sucrose was $30 \mathrm{~g} \cdot \mathrm{L}^{-1}$. But no beneficial effect of carbon dioxide enrichment was observed on the formation of secondary roots from $J$. nigra $\times$ J. regia 'A18' microcuttings at any sucrose level in the root elongation medium.

THE EFFECT OF TEMPERATURE. A higher percentage of shoots formed roots when root induction and elongation were performed at 22 than at $27{ }^{\circ} \mathrm{C}$ (data not shown). This increase was significant with J. nigra $\times$ J. regia 'A35', but not with 'A32'. For the first clone, $45 \%$ and $60 \%$ of shoots formed roots when cultures were maintained at a temperature of 27 and $22{ }^{\circ} \mathrm{C}$, respectively. However, the corresponding percentages of rooting were $45 \%$ and $43 \%$ with $J$. nigra $\times$ J. regia 'A32'.

The influence of A PRERooting CONDitioning CUlture. A 2-week-long transfer of shoots, before root induction, to G60 multiplication medium (Gruselle et al., 1995) supplemented with
$4.4 \mu \mathrm{M}$ BA was found to improve the percentage of rooting in $J$. nigra $\mathrm{X}$ J. regia 'A32', when compared with the control, without transfer ( 0 in Fig. 6). Moreover, the rooting was even better when the transfer was made to the G60 medium supplemented with 0.4 $\mu \mathrm{M}$ instead of $4.4 \mu \mathrm{M} \mathrm{BA}$. Transfer to this medium improved the quality of the rooted plantlets.

Leaves of plants were larger and greener than those from plants produced without a transfer or with a transfer to G60 supplemented with $4.4 \mu \mathrm{M}$ BA. The beneficial effect of the 2week-long transfer on the percentage of shoots forming roots, was genotype dependent. On J. nigra x J. regia 'A35' (Fig. 6B) and other hybrid clones, the same treatments induced no significant effects on the percentage of rooting. However, the quality improvement observed with 'A32' plantlets was also found with 'A35' and other hybrid clones.

ACClimatization OF PLANTLETS To soil. Emphasis was placed on improving not only the number of shoots forming roots but also the quality of the adventitious roots, and consequently increasing the survival of plantlets during the acclimatization to soil. Acclimatized walnut plantlets grown for $>1$ month in a 2 peat : 1 perlite substrate produced some new leaves and an extensive root system (Fig. 7). The percentage of acclimatized plants was genotype-dependent (data not shown), J. regia clones being more easily adapted to soil conditions than J. nigra $\mathrm{x} J$. regia clones.

Regardless of the genotype, the adjustment of auxin level during root induction, addition of vermiculite to the root elongation medium, lowering the sucrose content and carbon dioxide enrichment during the root elongation phase, favoured the formation of adventitious primary and secondary roots and consequently the survival of plantlets during acclimatization to soil was improved.

In conclusion, some $J$. regia walnut clones have been for the first time micropropagated following the protocol described here. A culture system initially set up for J. nigra $\times$ J. regia hybrid clones was modified and adapted for J. regia. Some factors have been found to improve not only the number of shoots forming adventitious roots but also the quality of their roots. Among these factors six have been the more prevailing: juvenility of the plant material, presence of vermiculite in the root elongation medium, a prerooting conditioning culture of shoot microcuttings, the auxin type and concentration, a lower sucrose content, and carbon dioxide enrichment during the root elongation phase. The reduction of the callus phase, the formation of numerous primary and secondary roots, and the leaf morphology, aparently associated with a higher photosynthetic activity, were improved after modifying the formerly mentioned factors. These resulted in increasing the percentage of rooted shoots and consequently the acclimatization of plantlets to soil.

\section{Literature Cited}

Aleta, N. and A. Ninot. 1993. Exploration and evaluation of spanish native walnut (J. regia L.) populations from catalonia and galicia. Acta Hort. 311:17-23.

Carmer, S.G. and R.D. Seif. 1963. Calculation of orthogonal coefficients when treatments are unequally replicated and/or unequally spaced. Agron. J. 55:387-389.

Cornu, D. and C. Jay-Allemand. 1989. Micropropagation of hybrid walnut trees (Juglans nigra $\mathrm{x}$ Juglans regia) through culture and multiplication of embryos. Ann. Sci. For. 46:113-116.

Dolcet-Sanjuan, R. and E. Claveria. 1995. Improved shoot-tip micropropagation of Pistacia vera $\mathrm{L}$. and the beneficial effects of methyl jasmonate. J. Amer. Soc. Hort. Sci. 120(6):938-942. 
Dolcet-Sanjuan, R., E. Claveria, A. Camprubi, V. Estaun, and C. Calvet. 1996. Micropropagation of walnut trees (Juglans regia L.) and response to arbuscular mycorrhizal inoculation. Agronomie 16:639-645.

Driver, J.A. and A.H. Kuniyuki. 1984. In vitro propagation of Paradox walnut rootstock. HortScience 19(4):507-509.

Gatineau, F., J.G. Fouché, C. Kevers, J.F. Hausman, and T. Gaspar. 1997. Quantitative variations of indolyl compounds including IAA, IAAaspartate and serotonin in walnut microcuttings during root induction. Biol. Plant. 39:131-137.

Gruselle, R. and P. Boxus. 1990. Walnut micropropagation. Acta Hort. $284: 45-52$

Gruselle, R., C. Nicaise, and P. Boxus. 1995. Regulation of in vitro shoot multiplication in Persian walnut by different carbon sources and by ammonium phosphate. Bul. Rech. Agron. Gembloux 30(1-2):47-53.

Heloir, M.C., C. Kevers, J.F. Hausman, R. Deltour, and T. Gaspar. 1994. Histological origin of roots of micropropagated walnut (Juglans regia) shoots. Arch. Intl. Physiologie, de Biochimie et de Biophysique 102(5): PP5.

Heloir, M.C., C. Kevers, J.F. Hausman, and T. Gaspar. 1996. Changes in the concentrations of auxins and polyamines during rooting of invitro-propagated walnut shoots. Tree Physiol. 16:515-519.

Jay-Allemand, C., P. Capelli, and D. Cornu. 1992. Root development of in vitro hybrid walnut microcuttings in a vermiculite-containing gelrite medium. Scientia Hort. 51:335-342.

Jay-Allemand, C. and D. Cornu. 1986. Culture in vitro d'embryons isolés de noyer commun (Juglans regia L.). Ann. Sci. For. 43:189-198.
Jay-Allemand, C., J. Dufour, and E. Germain. 1990. Détection précoce et rapide des noyers hybrides interspécifiques (Juglans nigra $\mathrm{x}$ Juglans regia) au moyen de critères morphologiques. Revue Hort. 311:39-41.

Lloyd, G. and B. McCown. 1980. Commercially feasible micropropagation of mountain laurel, Kalmia latifolia, by use of shoot-tip culture. Comb. Pro. Intl. Plant Prop. Soc. 30:421-427.

McGranahan, G., C.A. Leslie, and J.A. Driver. 1988. In vitro propagation of mature persian walnut cultivars. HortScience 23(1):220.

McGranahan, G.H., J.A. Driver, and W. Tulecke. 1987. Tissue culture of Juglans, p. 261-271. In: J.M. Bonga and D.J. Durzan (eds.). Cell and tissue culture in forestry. vol. 3. Case histories: Gymnosperms, angiosperms and palms. Martinus Nijhoff Publishers, Dordrecht.

McKenna, J., and E.G. Sutter. 1997. Adventitious root formation in walnut hybrid rootstocks (Juglans hindsii x J. regia), p. 85-90. In: A. Altman and Y. Waisel (eds.). Biology of root formation and development. Plenum Press, New York.

Murashige, T. and F. Skoog. 1962. Arevised medium for rapid growth and bio assays with tobacco tissue cultures. Physiol. Plant. 15:473-497.

Petersen, R.G. 1985. Design and analysis of experiments. 1st ed. Marcel Dekker Inc., NewYork.

Ripetti, V., C. Kevers, and T. Gaspar. 1994. Two successive media for the rooting of walnut shoots in vitro. Changes in peroxidase activity and ethylene production. Adv. Hort. Sci. 8:29-32.

Rodriguez, R.,A. Revilla, M.Albuerne, and C.Perez. 1989. Walnut(Juglans spp.), p. 99-126. In:Y.P.S. Bajaj (eds.). Biotechnology in agriculture and forestry. vol. 5. Tress II. Springer-Verlag, Berlin Heidelberg. 